\title{
Correlation of Asymmetric Dimethylarginine with Cardiovascular Disease in Prediabetes
}

\author{
Santosh Bidwe ${ }^{1}$, Prashant Hisalkar ${ }^{2}$, Neerja Mallick ${ }^{3}$
}

\begin{abstract}
Asymmetric dimethylarginine (ADMA) is now well established as a major risk factors for cardiovascular disease (CVD) impact upon endothelial function by decreasing nitric oxide $\left(\mathrm{NO}^{\circ}\right)$ bioavailability. Asymmetric dimethylarginine, an endogenous analog of $\mathrm{L}$-arginine, is able to inhibit the activity of endothelial-nitric oxide synthase (eNOS), promoting endothelial dysfunction. Prediabetes is characterized by a reduced endotheliumdependent vasodilation and increased ADMA levels. Asymmetric dimethylarginine is strongly associated with micro-and macrovascular diabetic complications. Asymmetric dimethylarginine activity is strongly correlated with CVD in prediabetes.

Materials and methods: This study was a cross-sectional, descriptive type of study. In total, 815 participants were involved in this study, out of which 250 suffered from type Il diabetes and 265 were prediabetic patients. 290 controls were involved from hospital OPD. Biochemical parameters including fasting plasma sugar, postprandial plasma sugar (after 2 hours of $75 \mathrm{~g}$ oral glucose), fasting lipid profile (serum total cholesterol (TC), low-density lipoprotein (LDL) cholesterol, triglycerides (TG), high-density lipoprotein (HDL) cholesterol, very low-density lipoprotein (VLDL) cholesterol) were done by enzymatic methods. The quantitative sandwich enzyme immunoassay technique was used to determine plasma ADMA level by using commercially available enzyme-linked immunosorbent assay.

Results: The level of ADMA in prediabetes was $0.55 \pm 0.11$ and of type II diabetes was $0.70 \pm 0.14$ compared with controls $(0.41 \pm 0.14)$. $p$ value was $<0.05$, which was significant. In the present study, there was a significant increase in serum TC, TG, LDL, VLDL, TG/HDL, and LDL/HDL ratio compared with those of normal healthy subjects, while HDL was significantly decreased in prediabetic as compared to normal healthy subjects. Conclusion: The current study shows that increased ADMA levels can indicate the risk of CVD in prediabetic stage. Prediabetes people are under risk of CVD and type II diabetes. Individuals who are prediabetic are at risk of CVD and type II diabetes. The evaluation of the ADMA levels may improve the early diagnosis of CVD of prediabetes.
\end{abstract}

Keywords: Asymmetric dimethylarginine, Cardiovascular disease, Nitric oxide, Prediabetes, Type II diabetes.

Indian Journal of Medical Biochemistry (2019): 10.5005/jp-journals-10054-0114

\section{INTRODUCTION}

Diabetes, which is defined as a fasting blood glucose level (FBGL) of greater than $6.9 \mathrm{mmol} / \mathrm{L}^{1}$ is associated with extensive organ dysfunction including diabetic retinopathy, kidney disease, and CVD, gastrointestinal disturbance, sexual dysfunction, and diabetic neuropathy. ${ }^{2,3}$ The fatal macrovascular complications account for the majority of deaths among patients with diabetes. ${ }^{4}$ Risk of CVD is already increasing in prediabetes patients, i.e., impaired glucose tolerance (IGT) patients who are defined as having FBGL of 5.6-6.9 $\mathrm{mmol} / \mathrm{L}$. Some studies represent that IFG is not just a precursor of diabetes, but an individual risk factor for death. The incidence of prediabetes is increasing globally to probably more than 400 million cases in 2030 and, if untreated, will progress to diabetes and the associated complications. ${ }^{5}$

Endothelial dysfunction was indicated as a major cardiovascular risk factor in various trials. ${ }^{3}$ Endothelial dysfunction is defined as a decrease in bioavailability of $\mathrm{NO}^{\circ}$, which inhibits the adhesion and aggregation of platelets, vascular smooth muscle cell proliferation, and LDL oxidation, and adhesion of monocytes and leukocytes to the endothelium. ${ }^{4}$ Asymmetric dimethylarginine is essentially a competitive inhibitor of eNOS. Asymmetric dimethylarginine regulates the production rate of $\mathrm{NO}^{\circ}$. Asymmetric dimethylarginine is degraded by enzyme dimethylarginine dimethyaminohydrolase (DDAH) plasma ADMA concentration has been shown to increase during the course of diseases associated with endothelial dysfunction such as diabetes mellitus, peripheral artery disease, hypertension, and CVD. ${ }^{6-10}$ \begin{tabular}{l}
\hline${ }^{1}$ Department of Biochemistry, SMBT Institute of Medical Sciences and \\
Research Centre, Nashik, Maharashtra, India \\
${ }^{2}$ Department of Biochemistry, Government Medical College and \\
Hospital, Dungarpur, Rajasthan, India \\
${ }^{3}$ Department of Biochemistry, People's University, Bhopal, Madhya
\end{tabular} Pradesh, India

Corresponding Author: Prashant Hisalkar, Department of Biochemistry, Government Medical College and Hospital, Dungarpur, Rajasthan, India, Phone: +91 9422610220, e-mail: pjhisalkar@yahoo. co.in

How to cite this article: Bidwe S, Hisalkar P, Mallick N. Correlation of Asymmetric Dimethylarginine with Cardiovascular Disease in Prediabetes. Indian J Med Biochem 2019;23(3):335-338.

Source of support: Nil

Conflict of interest: None

Cardiovascular disease is a large account fraction of morbidity and mortality in type II diabetes. ${ }^{11}$ Most of the studies were done on ADMA. Risk factors for CVD were clinically clear in diabetes mellitus, but it is not clear whether increased concentrations of ADMA are present in patients with IGT. In our view, there are hardly any studies available in Indian population regarding these biomarkers in prediabetes. The aim of present study was to evaluate serum ADMA level in prediabetes and type II diabetes patients and find the correlation with other variables.

(c) The Author(s). 2019 Open Access This article is distributed under the terms of the Creative Commons Attribution 4.0 International License (https://creativecommons. org/licenses/by-nc/4.0/), which permits unrestricted use, distribution, and non-commercial reproduction in any medium, provided you give appropriate credit to the original author(s) and the source, provide a link to the Creative Commons license, and indicate if changes were made. The Creative Commons Public Domain Dedication waiver (http://creativecommons.org/publicdomain/zero/1.0/) applies to the data made available in this article, unless otherwise stated. 


\section{Materials and Methods}

This study was done in the Department of Biochemistry, People's College of Medical Science and Research Center (PCMS and RC), Centre for Scientific Research and Development (CSRD), People's University, Bhopal. This is a cross-sectional descriptive study includes 250 type II diabetes patients, 265 prediabetes persons, and 290 controls during the period June 2017 to April 2019. Written informed consent was taken from all participants after applying inclusion and exclusion criteria. Sociodemographic data were collected by a self-designed questionnaire.

\section{Inclusion Criteria for Prediabetes According to American Diabetes Association}

- Age: between 18 years and 60 years

- Fasting blood sugar level: $100 \mathrm{mg}$ to $125 \mathrm{mg}$

- HbA1c: $5.7 \%$ to $6.4 \%$

- Postprandial blood sugar level (after 2 hours of $75 \mathrm{~g}$ oral glucose): 140 to $199 \mathrm{mg} / \mathrm{dL}$

\section{Exclusion Criteria for Prediabetes}

- Age more than 60 years and age less than 18

- Diagnosed diabetic patients

- Pregnant women

- HIV-positive patients

\section{Inclusion Criteria for Type II Diabetes According to American Diabetes Association}

- Age: between 18 years and 60 years

- Known case of type II diabetes (1-5 years) and HbA1c $6.5 \%$

\section{Exclusion Criteria for Type II Diabetes}

- Age not more than 60 years and age less than 18

- Pregnant women, HIV-positive patients

- Prolonged diabetes ( $>5$ years)

- Patients on statin therapy

The study protocol was approved by Institutional Ethics Committee. All the participants were screened for age, gender, fasting glucose level, postprandial glucose level, HbA1c, family history, and any medication history. Prediabetic cases were included and excluded with the help of physician, Department of Medicine, PCMS and RC. Biochemical parameters investigations are as follows (Table 1):

\section{Statistical Analysis}

The analysis was done using statistical package SPSS 24 and Microsoft Excel 2010. Independent $t$ test was used for comparison. " $p$ " value $<0.05$ was used for level of significance.

\section{Results}

A total of 815 subjects participated, and out of these 255 were type II diabetes patients, 270 were prediabetes, and 290 were controls in the present study.

The level of ADMA in prediabetes was $0.55 \pm 0.11$ and type II diabetes was $0.70 \pm 0.14$ compared with controls $0.41 \pm 0.14$. $p$ value was $<0.05$, which was significant (Table 2 and Fig. 1). Mean score of cholesterol in prediabetes was $243.34 \pm 20.03$ and type II diabetes was $311.92 \pm 60.86$ compared with controls $(170.81 \pm 22.34) . p$ value was $<0.001$, which was significant. Mean score of triglyceride in prediabetes was $169.89 \pm 14.33$ and type II diabetes was $191.32 \pm$ 40.96 compared with controls $(91.11 \pm 16.59)$. $p$ value was $<0.001$, which was significant. Mean score of HDL in prediabetes was $31.10 \pm 4.33$ and type II diabetes was $27.97 \pm 4.96$ compared with controls $(42.19 \pm 5.82)$. $p$ value was $<0.001$, which was significant. Mean score of LDL in prediabetes was $172.09 \pm 20.03$ and type II diabetes was $236.96 \pm 56.27$ compared with controls $(109.06 \pm 18.61)$. $p$ value was $<0.001$, which was significant. Mean score of VLDL in prediabetes was $36.07 \pm 7.04$ and type II diabetes was $47.56 \pm 10.45$ compared with controls (19.04 \pm 4.83$)$. $p$ value was $<0.001$, which was significant. Mean score of TG/HDL in prediabetes was $5.58 \pm 1.00$ and type II diabetes was $7.23 \pm 2.22$ compared with controls $(2.19 \pm$ $0.49)$. $p$ value was $<0.05$, which was significant. Mean score of LDL/ $\mathrm{HDL}$ in prediabetes was $5.74 \pm 1.08$ and type II diabetes was $8.94 \pm$ 3.43 compared with controls $(2.61 \pm 0.56)$. $p$ value was $<0.001$, which was significant (Table 2).

\section{Discussion}

It is well recognized that type II diabetes and its metabolic derangements such as hyperinsulinemia, hyperglycemia, dyslipidemia, and increased oxidative stress are associated with NO-mediated endothelial dysfunction. ${ }^{19}$ In contrast, endothelial dysfunction may lead to attenuated glucose uptake in insulinsensitive tissues, hyperglycemia, and ultimately to the development of insulin resistance and type II diabetes. ${ }^{20,21}$ Furthermore, impaired $\mathrm{NO}^{\circ}$ bioavailability plays a pivotal role in the regulation of glucose-stressed endothelial progenitor cell dysfunction in type II diabetes, and antioxidant treatment with superoxide dismutase may restore their function. ${ }^{22} \mathrm{ADMA}$, an endogenous competitive inhibitor of $\mathrm{NO}^{\circ}$ synthase, is known to impair $\mathrm{NO}^{\circ}$ bioavailability and endothelial function. ${ }^{23}$ Overexpression of DDAH, the enzyme

Table 1: Biochemical parameters of inclusion criteria for Prediabetes

\begin{tabular}{lll}
\hline S. no. & Biochemical parameters & Method \\
\hline 1 & Blood glucose & GOD-POD method \\
2 & Cholesterol & CHOD-POD method \\
3 & TG & Glycerol phosphate oxidase-peroxidase (GPO-POD method) ${ }^{14}$ \\
4 & HDL & Directly enzymatic colorimetric quantitative determination \\
5 & LDL & Friedewald equation assuming that TC is composed primarily \\
6 & VLDL & By calculation \\
7 & HbA1c & Enzymatic method $^{16}$ \\
8 & ADMA & ELISA method $^{17,18}$ \\
\hline
\end{tabular}


Table 2: Comparison of endothelial dysfunction biomarkers in prediabetes and type ll diabetes compared with controls

\begin{tabular}{lllll}
\hline Variables & Control & Prediabetes & Type ll diabetes & $p$ value \\
\hline Age & $37.46 \pm 10.42$ & $45.70 \pm 8.98$ & $43.09 \pm 10.88$ & $<0.001$ \\
Gender (M/F) & $159 / 131$ & $168 / 102$ & $148 / 107$ & - \\
HbA1c (\%) & $5.07 \pm 0.35$ & $6.01 \pm 0.19$ & $8.2 \pm 1.19$ & $<0.001$ \\
Cholesterol mg/dL & $170.81 \pm 22.34$ & $243.34 \pm 20.03$ & $311.92 \pm 60.86$ & $<0.001$ \\
TG mg/dL & $91.11 \pm 16.59$ & $169.89 \pm 14.33$ & $191.32 \pm 40.96$ & $<0.001$ \\
HDL mg/dL & $42.19 \pm 5.82$ & $31.10 \pm 4.33$ & $27.97 \pm 4.96$ & $<0.001$ \\
LDL mg/dL & $109.06 \pm 18.61$ & $172.09 \pm 20.03$ & $236.96 \pm 56.27$ & $<0.001$ \\
VLDL mg/dL & $19.04 \pm 4.83$ & $36.07 \pm 7.04$ & $47.56 \pm 10.45$ & $<0.001$ \\
TG/HDL & $2.19 \pm 0.49$ & $5.58 \pm 1.00$ & $7.23 \pm 2.22$ & $<0.05$ \\
LDL/HDL & $2.61 \pm 0.56$ & $5.74 \pm 1.08$ & $8.94 \pm 3.43$ & $<0.001$ \\
ADMA $(\mu \mathrm{mol} / \mathrm{L})$ & $0.41 \pm 0.14$ & $0.55 \pm 0.11$ & $0.70 \pm 0.14$ & $<0.05$ \\
\hline
\end{tabular}

$p<0.05$ is consider as statistically significant

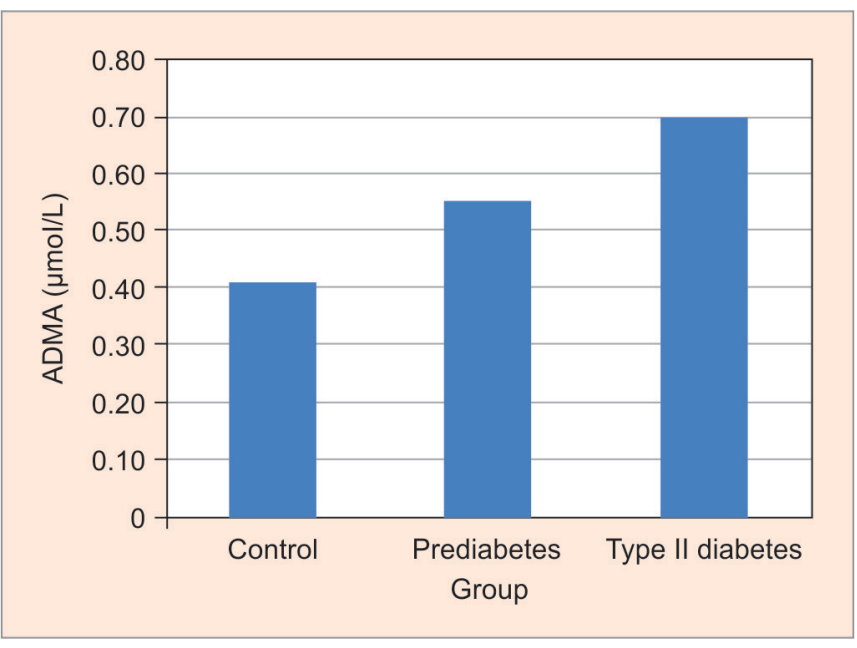

Fig. 1: Mean score of ADMA

responsible for the elimination of ADMA in human, may lead to reduced plasma ADMA level and enhance insulin sensitivity. ${ }^{24}$ In human studies, insulin resistance is related to plasma ADMA concentration, impaired ability of enzyme DDAH, and treatment with rosiglitazone, and weight reduction enhances insulin sensitivity and significantly lowers plasma ADMA level. ${ }^{25,26}$ Plasma ADMA level has been reported to be correlated with treadmill stress test-derived outcome parameters ${ }^{27}$ and asymptomatic carotid atherosclerosis. ${ }^{28}$ In prediabetic subjects, elevated ADMA was strongly associated with increased arterial stiffness, which is a wellestablished predictor of cardiovascular outcomes. ${ }^{29}$ Hyperglycemia is associated with endothelial dysfunction both in vivo ${ }^{30}$ and in vitro; ${ }^{31}$ therefore, endothelial dysfunction is an early feature in the development of vascular complications in people with diabetes. These findings suggest that the elevated ADMA in diabetes could contribute to accelerated atherosclerosis in this population. ${ }^{32}$

Studies comparing ADMA levels of prediabetic subjects with healthy people are inconclusive. Although some studies report increased ADMA levels in prediabetes. ${ }^{33}$ Eliana et al. report no significant difference between groups. Associations between increased levels of ADMA and many cardiovascular risk factors such as age, hypertension, diabetes, insulin resistance, hypercholesterolemia, hypertriglyceridemia, smoking, and BMI have been accepted. ${ }^{34}$ In our study, we found that ADMA levels were elevated in prediabetes and type II diabetes compared with healthy controls.

In our study, plasma ADMA levels were significantly increased in the prediabetes and type II diabetes compared with the control group. We suggest that increased ADMA levels could contribute to impaired endothelial function in prediabetic stage. Recent studies have indicated that LDL particle concentrations, and specifically LDL levels, are predictors of coronary events, and it is an independent coronary disease risk factor. ${ }^{35}$ At the molecular level, high LDL-C levels induce endothelial cell dysfunction with subsequent decreased $\mathrm{NO}^{\circ}$ bioavailability due to impaired L-arginine transport and metabolism and eNOS uncoupling. Peroxynitrite, the major uncoupling byproduct of eNOS, has been reported to directly damage elastin. ${ }^{36}$ Studies show that subjects with the metabolic syndrome and/or DM have higher sLDL levels than controls. ${ }^{37,38}$ In our study, we find a significant difference in serum lipid profile levels between the groups.

\section{Conclusion}

The current study shows increased ADMA levels can indicate the risk of CVD in prediabetic stage and type II diabetes. The evaluation of the ADMA levels may improve the early diagnosis of CVD in prediabetes patients. Along with routine investigations, an early detection of ADMA will help the clinicians to plan line of treatment in a better manner. Well-balanced nutrition, patient education, diet counseling, and supplementation therapies for high risk group of diabetic patients are strongly recommended.

The outcome of our study is to know the role of ADMA in prediabetes and diabetes in clinical manifestations of the disease, which ultimately helps us in better management of the patient. This study will help us develop the criteria for preventive measures of the disease using biochemical markers in predicting the disease.

\section{References}

1. American Diabetes Association. Diagnosis and classification of diabetes mellitus. Diabetes Care 2004;27:5-10. DOI: 10.2337/ diacare.27.2007.S5.

2. Romeo JH, Seftel AD, Madhun ZT, et al. Sexual function in men with diabetes type II: association with glycemic control. J Urol 2000;163:788-791. DOI: 10.1016/S0022-5347(05)67805-6. 
3. Cade WT. Diabetes-related microvascular and macrovascular diseases in the physical therapy setting. Phys Ther 2008;88:1322-1335. DOI: 10.2522/ptj.20080008.

4. Rahman S, Rahman T, Ismail AA-S, et al. Diabetes-associated macrovasculopathy: pathophysiology and pathogenesis. Diabetes Obes Metab 2007;9:767-780. DOI: 10.1111/j.1463-1326.2006.00655.x.

5. Tabák AG, Herder C, Rathmann W, et al. Prediabetes: Ahigh-risk state for diabetes development. Lancet 2012;379:2279-2290. DOI: 10.1016/ S0140-6736(12)60283-9.

6. Anderson JL, Carlquist JF, Roberts $\mathrm{WL}$, et al. Asymmetric dimethylarginine, cortisol/cortisone ratio, and C-peptide: markers for diabetes and cardiovascular risk? Am Heart J 2007;153:67-73. DOI: 10.1016/j.ahj.2006.10.014.

7. Wilson AM, Shin DS, Weatherby C, et al. Asymmetric dimethylarginine correlates with measures of disease severity, major adverse cardiovascular events and allcause mortality in patients with peripheral arterial disease. Vasc Med 2010;15:267-274. DOI: 10.1177/1358863X10364552.

8. Achan V, Broadhead M, Malaki M, et al. Asymmetric dimethylarginine causes hypertension and cardiac dysfunction in humans and is actively metabolized by dimethylarginine dimethylaminohydrolase. Arterioscler Thromb Vasc Biol 2003;23:1455-1459. DOI: 10.1161/01. ATV.0000081742.92006.59.

9. Schulze F, Lenzen $\mathrm{H}$, Hanefeld C, et al. Asymmetric dimethylarginine is an independent risk factor for CHD: results from the multicenter Coronary Artery Risk Determination investigating the Influence of ADMA Concentration (CARDIAC) study. Am Heart J 2006;152:493-498. DOI: 10.1016/j.ahj.2006.06.005.

10. Bal UA, Yıldırır A, Aydinalp A, et al. Could plasma asymmetric dimethylarginine level be a novel predictor beyond the classic predictors of stent restenosis? Anadolu Kardiyol Derg 2014;14: 491-497. DOI: 10.5152/akd.2014.4922.

11. Patel VB, Robbins MA, Topol EJ. C-reactive protein: a "golden marker" for inflammation and coronary artery disease. Cleve Clin J Med 2001;68:521-534. DOI: 10.3949/ccjm.68.6.521.

12. Kaplan LA. Carbohydrates and metabolite. In Clinical Chemistry: theory, Analysis and co-relation, Kaplan LA, Pesce AJ. ed., Toronto: C.V. Obsy; 1984. pp. 1032-1040.

13. Allain CC, Poon L, Chan CS, et al. Enzymatic determination of total serum cholesterol. Clin Chem 1974;20(4):470-475.

14. Rifal N, Bachorik PS, Albers JJ. Lipoproteins and apolipoproteins. In: Burtie CA, Ashwood ER. Tietz Textbook of Clinical Chemistry, 3rd ed., Philadelphia: W.B. Saunders Company; 1999. pp. 809-861.

15. Williams $P$, Robinson D, Bailey A. High density of lipoprotein and coronary risk factor in normal man. Lancet 1979;1:72. DOI: 10.1016/ S0140-6736(79)90063-1.

16. Japan Diabetes Society. ed., Treatment Guide for Diabetes, vol. 9. Bunkodo; 2010.

17. Schulze F, Wesemann R, Schwedhelm E, et al. Determination of ADMA using a novel ELISA assay. Clin Chem Lab Med 2004;42:1377-1383. DOI: $10.1515 / C C L M .2004 .257$.

18. Schulze F, Maas $R$, Freese $R$, et al. Determination of a reference value for $\mathrm{N}, \mathrm{N}$-dimethyl-L-arginine in 500 subjects. Eur J Clin Invest 2005;35:622-626. DOI: 10.1111/j.1365-2362.2005.01561.x.

19. Schalkwijk CG, Stehouwer CD. Vascular complications in diabetes mellitus: the role of endothelial dysfunction. Clin Sci 2005;109: 143-159. DOI: 10.1042/CS20050025.

20. Steinberg HO, Brechtel G, Johnson A, et al. Insulinmediated skeletal muscle vasodilation is nitric oxide dependent. A novel action of insulin to increase nitric oxide release. J Clin Invest 1994;94:1172-1179. DOI: $10.1172 / \mathrm{JCI} 117433$.

21. Vincent MA, Clerk LH, Lindner JR, et al. Microvascular recruitment is an early insulin effect that regulates skeletal muscle glucose uptake in vivo. Diabetes 2004;53:1418-1423. DOI: 10.2337/diabetes. 53.6.1418.
22. Hamed S, Brenner B, Aharon A, et al. Nitric oxide and superoxide dismutase modulate endothelial progenitor cell function in type II diabetes mellitus. Cardiovasc Diabetol 2009;8:56. DOI: 10.1186/14752840-8-56.

23. Böger RH, Bode-Böger SM, Tsao PS, et al. An endogenous inhibitor of nitric oxide synthase regulates endothelial adhesiveness for monocytes. J Am Coll Cardiol 2000;36:2287-2295. DOI: 10.1016/ S0735-1097(00)01013-5.

24. Stühlinger MC, Abbasi F, Chu JW, et al. Relationship between insulin resistance and an endogenous nitric oxide synthase inhibitor. JAMA 2002;287:1420-1426. DOI: 10.1001/jama.287.11.1420.

25. Mclaughlin T, Stühlinger M, Lamendola C, et al. Plasma asymmetric dimethylarginine concentrations are elevated in obese insulinresistant women and fall with weight loss. J CLin Endocrine Metab 2006;91:1896-1900. DOI: 10.1210/jc.2005-1441.

26. Sydow K, Mondon CE, Schrader J, et al. Dimethylarginine dimethylaminohydrolase overexpression enhances insulin sensitivity. Arterioscler Thromb Vasc Biol 2008;28:692-697. DOI: 10.1161/ ATVBAHA.108.162073.

27. Deftereos S, Bouras G, Tsounis D, et al. Association of asymmetric dimethylarginine levels with treadmill-stress-test-derived prognosticators. Clin Biochem 2014;47:593-598. DOI: 10.1016/ j.clinbiochem.2014.01.031.

28. Riccioni G, Scotti L, D'Orazio N, et al. ADMA/SDMA in elderly subjects with asymptomatic carotid atherosclerosis: values and sitespecific association. Int J Mol Sci 2014;15:6391-6398. DOI: 10.3390/ ijms15046391.

29. Protopsaltis I, Foussas S, Angelidi A, et al. Impact of ADMA, endothelial progenitor cells and traditional cardiovascular risk factors on pulse wave velocity among prediabetic individuals. Cardiovasc Diabetol 2012;11:141. DOI: 10.1186/1475-2840-11-141.

30. Kawano H, Motoyama T, Hirashima O, et al. Hyperglycemia rapidly suppresses flow-mediated endothelium dependent vasodilation of brachial artery. J Am Coll Cardiol 1999;34(1):146-154. DOI: 10.1016/ S0735-1097(99)00168-0.

31. Cosentino F, Hishikawa K, Katusic ZS, et al. High glucose increases nitric oxide synthase expression and superoxide anion generation in human aortic endothelial cells. Circulation 1997;96(1):25-28. DOI: 10.1161/01.CIR.96.1.25.

32. Jawalekar SL, Karnik A, Bhutey A. Risk of cardiovascular diseases in diabetes mellitus and serum concentration of asymmetrical dimethylarginine. Biochem Res Int 2013;2013:189430. DOI: $10.1155 / 2013 / 189430$.

33. Surdacki A, Stochmal E, Szurkowska M, et al. Nontraditional atherosclerotic risk factors and extent of coronary atherosclerosis in patients with combined impaired fasting glucose and impaired glucose tolerance. Metabolism 2007;56(1):77-86. DOI: 10.1016/ j.metabol.2006.08.023.

34. Eliana F, Suwondo P, Makmun LH, et al. AADMA as a marker of endothelial dysfunction in prediabetic women. Acta Med Indones 2011;43(2):92-98.

35. Kathiresan S, Otvos JD, Sullivan LM, et al. Increased small lowdensity lipoprotein particle number: a prominent feature of the metabolic syndrome in the Framingham Heart Study. Circulation 2006;113(1):20-29. DOI: 10.1161/CIRCULATIONAHA.105.567107.

36. Zhang WZ, Venardos K, Finch S, et al. Detrimental effect of oxidized LDL on endothelial arginine metabolism and transportation. Int J Biochem Cell Biol 2008;40:920-928. DOI: 10.1016/j.biocel.2007.10.027.

37. Yoshino G, Hirano T, Kazumi T. Atherogenic lipoproteins and diabetes mellitus. J Diabetes Complications 2002;16(1):29-34. DOI: 10.1016/ S1056-8727(01)00199-4.

38. Nakano S, Kuboki K, Matsumoto T, et al. Small, dense LDL and highsensitivity C-reactive protein (hsCRP) in metabolic syndrome with type II diabetes mellitus. J Atheroscler Thromb 2010;17(4):410-415. DOI: 10.5551/jat.1891. 